\title{
A CONSTRUÇÃO DA VERDADE E A GESTÃO DA INFORMAÇÃO NA CENTRAL DISQUE-DENÚNCIA $^{1} / /$ Mariana dos Santos Vianna ${ }^{2}$ e Pedro Heitor Barros Geraldo ${ }^{3}$
}

\author{
Palavras-chave \\ informação / análise criminal / gestão / Disque- \\ Denúncia / segurança pública
}

HIIIIIIIIIIIIIIIIIIIIIIIIIIIIIIIII

\section{Sumário}

1 Introdução

2 A organização da Central Disque-

Denúncia

3 Central de Atendimento Telefônico:

Atendimento e Denúncia

4 A importância do relato: procedimento de construção da denúncia

5 Setor de Análise: Pesquisas e Relatórios

6 Compartilhamento e Particularização da Informação

\begin{abstract}
Resumo
Este artigo descreve e analisa o processo de construção da verdade e da gestão da informação na Central Disque-Denúncia a partir da observação das práticas de recebimento das denúncias, mas também da organização e gestão da informação pelo Setor de Análise. O objetivo é compreender como a instituição - diferentemente de outras instituições de segurança públi$\mathrm{ca}$ - atua nos processos de produção da informação e de construção da verdade e como elabora a sua política de gestão da informação através da difusão de dados e relatórios. Esta análise compreende as formas de produção da informação pelos "relatórios" cujas finalidades são específicas. Demonstra-se como as informações obtidas pela Central de Atendimento da Central Disque-Denúncia são importantes para a produção de relatórios do Setor de Análise e como os analistas se relacionam com os agentes da segurança pública a partir de uma atividade não-inquisitorial de gestão da informação. Como conclusão, a pesquisa demonstra as diferenças entre as formas transparentes e as formas inquisitoriais de gestão da informação.
\end{abstract}

10 presente artigo é uma versão revisada do trabalho apresentado no V ENADIR - Encontro Nacional de Antropologia do Direito (2017). GT.04 - Processo, construção da verdade jurídica e decisão judicial. 2 Bacharel em Segurança Pública pela Universidade Federal Fluminense: marianaviannads@gmail.com

3 Doutor em Ciência Política pela Université Montpellier. Professor Adjunto do Departamento de Segurança Pública do Instituto de Estudos Comparados em Administração de Conflitos da Universidade Federal Fluminense: pedroheitorbg@yahoo.com.br 


\section{THE MAKING OF THE TRUTH AND INFORMATION MANEGEMENT AT THE DISQUE-DENÚNCIA (POLICE HOTLINE) // Mariana dos Santos Vianna and Pedro Heitor Barros Geraldo}

\author{
Keywords \\ information / criminal analysis / management / \\ Disque-Denúncia police hotline / public safety
}

HIIIIIIIIIIIIIIIIIIIIIIIIIIIIIIII

\begin{abstract}
This article describes and analyzes the process of construction of truth and information management in the Disque-Denúncia Central (Police Hotline) from observation of practices of the receipt of complaints, but also of the organization and information management by the Analysis Sector. The goal is to understand how the institution - unlike other public security institutions - acts on the processes of information production and construction of truth, as well as the information management policy through the diffusion of information and reports. This analysis comprises the forms of production of information by "reports", which have specific purposes. It is demonstrated how the information obtained by the hotline of the Disque-Denúncia Central are important to the production of Analysis Sector reports and how analysts relate to public security officer from a non-inquisitorial activity of information management. In conclusion, the research demonstrates the differences between transparent forms and inquisitorial forms of information management.
\end{abstract}




\section{Introdução}

Esta pesquisa analisa as formas de produção e gestão da informação pela Central Disque-Denúncia a partir de observação participante e análise dos relatórios produzidos por seus membros. Estes são as principais atividades do " $D D$ ", como seus membros o chamam. A pesquisa demonstra a forma não-inquisitorial de coleta das denúncias e do compartilhamento com outras instâncias.

A Central Disque-Denúncia é uma central de atendimento telefônico que recebe ligações denunciando práticas consideradas criminosas pelos denunciantes, as quais são registradas por atendentes e encaminhadas para os órgãos e instituições competentes. Esses registros permanecem armazenados no banco de dados onde poderão ser acessados a qualquer tempo. A partir da continuidade desses registros é possível produzir relatórios de análise criminal tendo como base as informações neles contidas.

No Brasil, a cultura inquisitorial da polícia (Kant De Lima, 1995, 1999; Holloway, 1997; Mendes de Miranda et al, 2007; Paes, 2010) orienta que os membros do Estado devem verificar a veracidade dos fatos narrados à autoridade policial. Esse procedimento é realizado através da verificação da procedência da informação (VPI) que "aparece como um instrumento de averiguação da credibilidade daquilo que é informado por qualquer pessoa que não faça parte da instituição policial" (Freixo, 2013, p. 20). Desta forma, ao apresentar uma denúncia, a suspeita também recai sobre quem denuncia, não sendo apenas direcionada a quem foi e ao que foi denunciado, devido ao caráter negativo que a denúncia apresenta.

Contrariamente a essa onipotência do Estado e à perspectiva jurídica brasileira, segundo a qual a versão denunciada deve ser semelhante à versão construída pela própria polícia, o " $D D$ " não coleta relatos suspeitando de sua veracidade, mas apostando em seu potencial informativo.

Da perspectiva institucional, a denúncia é constituída a partir do registro das informações fornecidas pelos denunciantes, o qual é realizado por atendentes que compõem o relato. Portanto, as denúncias consideradas boas, e que posteriormente poderão ser usadas para a produção de análises criminais a partir dos relatórios, não se referem às denúncias verificadas ou verdadeiras, mas àquelas que contêm descrições capazes de qualificar detalhadamente alguma atividade percebida como criminosa pelo denunciante.

A análise do trabalho realizado na Central Disque-Denúncia engloba o trabalho de todos os setores presentes na instituição, principalmente da Central de Atendimento e do Setor de Análise. Desta forma, através da descrição detalhada das atividades cotidianas desses setores, buscamos com esta pesquisa analisar o processo de construção do relato a partir do recebimento de ligações pelos atendentes na Central de Atendimento - "o coração da central" -, e a gestão dessas informações que contribuem para ações policiais e ações voltadas às políticas de segurança, tanto públicas quanto privadas.

\section{A organização da Central Disque- Denúncia}

A Central Disque-Denúncia é um serviço de atendimento telefônico oferecido à população por meio de uma instituição privada e sem fins lucrativos - o Instituto MovRio -, que põe em prática seu funcionamento a partir de financiamentos de empresas através de convênios, patrocínios, parcerias e contribuições. Além desses financiamentos, a instituição possui uma relação com o Estado no que diz respeito a sua estrutura física, à ajuda financeira provida pela Secretaria de Estado de Segurança (SESEG) e às relações de reciprocidade estabelecidas entre agentes da segurança pública e seus "parceiros".

Aos atendentes são atribuídas as atividades de receber ligações e registrá-las em seus respectivos terminais. As denúncias geradas pelas ligações são registradas e, em seguida, encaminhadas para o setor de Difusão. Esse setor, responsável pela difusão das denúncias aos órgãos competentes, é composto por agentes de instituições de segurança pública, como a Polícia Militar, o Corpo de Bombeiros Militar e a Polícia Civil, todos do estado do Rio de Janeiro.

A organização da instituição também possui uma gerência de cobrança por respostas das denúncias, principalmente daquelas classificadas como ime- 
diatas. O procedimento é de inclusão no sistema das respostas retornadas pelas instituições. Há ainda os setores responsáveis pela confecção de cartazes de foragidos que estão sendo procurados pela justiça e de pessoas desaparecidas. Também há outros setores responsáveis por denúncias de violência doméstica e crimes ambientais. Todos os setores e atividades são monitorados por uma Coordenação Geral que está vinculada à Gestão da Central Disque-Denúncia que é de responsabilidade de uma entidade civil, a MOVRIO.

\section{Central de Atendimento Telefônico: Atendimento e Denúncia}

A Central de Atendimento do " $D D$ ” recebe uma média de 14 a 20 ligações diárias por atendente, segundo o próprio “DD”, as quais podem ser classificadas como atendimento ou denúncia.

Para os atendentes, toda ligação que não se torna denúncia é classificada como atendimento e gera um número de protocolo. 0 atendimento acontece quando quem liga quer alguma informação ou fazer um elogio, ou quando a ligação cai, quando é engano, podendo ser também pedidos de socorro, reclamações, solicitações e pedidos de providência de denúncias anteriormente registradas, além de trotes. Esses atendimentos se distinguem daqueles realizados por instituições de segurança pública, principalmente delegacias de polícia civil onde casos podem ser classificados como feijoada - desentendimentos que, segundo os policiais, lhes dão trabalho e geram poucos resultados e penalizações brandas - e, consequentemente, são bicados da delegacia, fazendo com que as pessoas procurem outros lugares para administrar seus conflitos. Estas categorias nativas da polícia civil se referem às "avaliações policiais que decidem se um conflito é ou não fato a ser considerado válido para ser atendido com registro de ocorrência, documento que pode iniciar uma investigação policial” (Souza, 2008, p. 1), segundo valores e moralidades presentes na cultura policial (Kant de Lima, 1995; Souza, 2008).

Diferentemente das delegacias de polícia civil, os atendentes do " $D D$ " recebem todas as ligações e são indiferentes à sua classificação como denúncia ou atendimento para registro no sistema. Uma ligação é classificada como atendimento quando não é possível coletar nenhuma informação que possa ser registrada e fazer parte do banco de dados do sistema da instituição.

Uma ligação é identificada como denúncia quando quem liga oferece informações referentes a ações percebidas como criminosas, desde ligações clandestinas de luz a tráfico de drogas e homicídios. Os conteúdos dos relatos explicitam muitas vezes "um mundo social feito de um especial embaralhamento entre o formal e o informal, o legal e ilegal, o lícito e o ilícito" (Telles; Hirata, 2007, p. 179). Para os membros do "DD", a denúncia é toda informação que pode ter utilidade, seja instantaneamente ou futuramente. A denúncia "pode relatar um evento, identificar um local, contar um pedaço de uma história, ou mesmo trazer em seu conteúdo o mesmo fato anteriormente denunciado de outra forma” (Moraes, 2006, p. 40).

As ligações classificadas como denúncia são registradas no sistema e geram números de protocolo, informado ao denunciante para que ele possa acompanhar o andamento da denúncia, ou acrescentar-lhe mais informações, fazendo parte de um sistema de registro contínuo, que sempre pode ser completado, emendado e corrigido. Como consequência, os registros permanecem acessíveis aos denunciantes e aos demais atendentes. Além disso, o número de protocolo permite identificar as denúncias que redundaram em operações exitosas. Esse número despersonaliza o denunciante, resguardando sua identidade, a fim de realizar a política de recompensas do " $D D$ ".

Após determinar que uma ligação é denuncia, ela pode ser classificada como normal e importante, podendo ser também classificada como imediata. Segundo um dos atendentes, uma denúncia normal ocorre quando o que foi denunciado é algo corriqueiro, já aconteceu ou acontece com frequência e precisa de um tempo para ser investigado, como por exemplo, o tráfico de drogas. Por outro lado, a denúncia classificada como importante está relacionada a algo que está em evidência na mídia, de apuração rápida e/ou sobre determinados tipos de crime como, por exemplo, informações sobre algum traficante que está em evidência para a polícia ou crimes contra vulneráveis, como crianças, adolescentes, idosos e pessoas com deficiência. 
A denúncia normal e a denúncia importante também podem ser classificadas como imediatas, quando o fato denunciado está acontecendo ou vai acontecer em um determinado espaço de tempo e/ou quando a vítima está ferida ou em situação de risco extremo, como cárcere privado, agressões e ameaças, por exemplo. Não há um protocolo exato de quais denúncias deverão ser classificadas como normais ou importantes e/ou imediatas. Isso depende da experiência do atendente, que define o grau de prioridade das denúncias em razão dessa política de gestão da informação, em que "tudo é importante" e é orientado para compartilhar.

O caráter imediato de uma denúncia tem relação direta com a sua qualidade, já que se refere à natureza do que é denunciado e/ou à quantidade de informações nela contida. Para os membros da instituição, todas as denúncias são presumidamente úteis, tendo em vista que poderão ser aproveitadas futuramente (ou não) para a produção de relatórios. A incerteza quanto à sua utilidade faz com que todas as denúncias sejam significativas, imprescindíveis do ponto de vista de sua coleta e seu registro. Segundo Garfinkel (2014),

saber se o que foi reunido se revelará inútil ou não, afinal de contas, e se terá de ser coletado novamente, dependerá de restrições impostas pela necessidade de formular perguntas para as quais os arquivos oferecem respostas que o investigador está disposto a aceitar (2014, p. 100).

Comparando com o procedimento inquisitorial de coleta de informações presentes nas instituições policiais e jurídicas, o procedimento não-inquisitorial do Disque-Denúncia permite que as informações sejam coletadas e circulem sem que a veracidade seja colocada em questão e sem que ela seja imediatamente útil, o que não ocorre nas instituições anteriormente citadas, tendo como exemplo os cartórios (Mendes de Miranda, 2000) e a polícia (Kant de Lima 1995, 1999; Mendes de Miranda et al, 2007).

Em sua etnografia sobre o Setor de Descoberta de Paradeiros da Divisão de Homicídios do Rio de Janeiro, Ferreira (2015) aborda outro aspecto referente às rotinas e às quebras de rotinas dentro das delegacias em casos de comunicação de um desaparecimento.
A autora apresenta que "a lógica cartorial vigente em repartições policiais responde também à exigência de estabelecer a veracidade do que fica depositado nos documentos, incidindo de forma determinante sobre os processos de produção de verdades judiciárias" (Ferreira, 2015, pp. 83-84). Desta forma, Ferreira explicita que, apesar de os fatos serem levados à delegacia e registrados pelos agentes, possuindo fé pública, a responsabilidade sobre a veracidade daquilo que foi comunicado também recai sobre aquele que procura a delegacia, sendo isso expresso pela redação e assinatura do termo de declarações.

O Disque-Denúncia não tem o propósito de reter ou testar a veracidade da informação, como ocorre em outras instituições, havendo assim uma indiferença quanto à veracidade da informação. A instituição se orienta pelo compartilhamento da informação e a relação de confiança com o denunciante, haja vista que não se pressupõe uma suspeita a priori da veracidade da informação e nem daquele que denuncia.

\section{A importância do relato: procedimento de construção da denúncia}

Ao receber uma ligação e identificá-la como denúncia, tem início a construção do relato. Para ser uma denúncia, as informações fornecidas precisam conter, principalmente, três elementos: primeiro, informações sobre práticas que os denunciantes identificam como criminosas e que estão ou não presentes no sistema, possibilitando alguma intervenção; segundo, informações que contribuam para a composição do banco de dados; terceiro, não conter, em hipótese alguma, qualquer informação que possa identificar o denunciante, cuja anonimato será garantido.

Diferentemente do que acontece nos call centers, onde os atendentes são orientados por scripts no ato do atendimento (Souza et al., 2015), a construção do relato pelos atendentes do " $D D$ " não é orientada por questionários prontos e mandatórios. Segundo as políticas de gestão de informação do " $D D$ ", roteiros seriam inadequados para a atividade dos atendentes, pois "nenhuma denúncia é igual a outra". Porém, existem perguntas que são orientadoras para a construção do relato, como: "Onde? Quem? Por quê? Como? Já aconteceu ou está acontecendo? Com que 
frequência acontece?" Outras questões dependem da situação e do conteúdo da denúncia.

A produção de relatos bem qualificados depende da "curiosidade" dos atendentes em entrevistar os denunciantes. Essa "curiosidade" é orientada para produzir uma completude de descrições sobre pessoas, lugares e situações. Os atendentes não esperam verificar os registros, mas produzir relatos potencialmente articuláveis com outros aparentemente desconexos. Entretanto, os interesses futuros sobre o conjunto dos relatos podem variar segundo as finalidades dos relatórios produzidos.

O registro das informações no banco de dados da instituição e, posteriormente, a produção sistematizada de relatórios baseados nesses registros necessitam de procedimentos qualificados de coleta de informações visando ao detalhamento das informações. Para tanto, os atendentes consideram que é necessário ter habilidade, na conversa, para orientar o relato do denunciante, visando à coleta de informações que aparentemente são irrelevantes do ponto de vista do próprio denunciante. Do ponto de vista dos atendentes, "todas as informações são importantes". Desta forma, interesse, cuidado, paciência e saber dialogar são as habilidades mais importantes que um atendente deve ter para coletar as informações ao desenvolver a escuta, a entrevista e a redação dos relatos.

A forma como os registros são produzidos faz parte de uma política institucional na qual é imprescindível registrar todas as informações, não importando se elas serão futuramente úteis ou não, ou se o que foi denunciado é verdadeiro ou não. Portanto, não há denúncias ruins ou falsas, pois todas as informações obtidas através das denúncias são consideradas importantes. Porém, há aquelas que são mais completas e que poderão ser utilizadas para a produção de análise criminal através dos relatórios.

Essa experiência é orientada pelas políticas de gestão da informação que consideram que os relatos têm sempre um potencial informativo para um futuro interessado. As pesquisas sobre interações em contextos institucionais demonstram como os profissionais são capazes de antecipar as consequências dos potenciais usos dos relatos. Dupret (2011) explica como os relatos produzidos em instâncias judiciais são objetos de novas interpretações para produzir as consequências inicialmente potenciais desses mesmos relatos. Para os membros do "DD", a qualidade da denúncia está relacionada a esses potenciais usos futuros, uma vez que a organização dos registros por meio de relatórios é capaz de produzir um conhecimento sobre lugares, pessoas e situações articulando diferentes relatos registrados ao longo do tempo (Vianna; Geraldo, 2017).

\section{Setor de Análise: Pesquisas e Relatórios}

A Central Disque-Denúncia não funciona somente como uma central de atendimento telefônico que recebe ligações. Apesar de esse ser o principal trabalho realizado pela instituição, o " $D D$ " também dispõe de outros setores responsáveis por desenvolver outras atividades. Dentre eles está a Difusão, que repassa às instituições as denúncias registradas, e o Setor de Análise, responsável pela produção de análises criminais.

As pesquisas e os relatórios são realizados para as instituições de segurança pública, e também são solicitadas por empresas privadas e pela imprensa. Para a realização das pesquisas e para a produção dos relatórios de análise criminal é preciso ler cada denúncia e selecionar aquelas que condensam mais informações, tendo em vista que muitas se repetem.

Pesquisas e relatórios são produtos distintos. As pesquisas são referentes a denúncias registradas no sistema sobre determinados assuntos, bairros etc. São realizadas de forma simples: é necessário o preenchimento dos filtros presentes no sistema com os dados fornecidos pelo solicitante, sendo o filtro principal certas palavras constantes do relato. As pesquisas podem ser quantitativas ou qualitativas. $A$ partir dos filtros preenchidos, o sistema lista todas as denúncias e elas são geradas em um único arquivo, contendo informações como: data, hora, relato, endereço, envolvidos e para onde foram difundidas. 0 conteúdo integral da pesquisa é encaminhado para policiais, para instituições policiais, para a SSI (Subsecretaria de Inteligência) e para órgãos do sistema de justiça, como o Ministério Público. 
Os relatórios, por sua vez, são produções mais completas e complexas construídas com o auxílio de outros mecanismos de informação (redes sociais, notícias, sites que abordam o assunto), além das pesquisas. Desta forma, podemos dizer que os relatórios são uma espécie de análise criminal realizada através das informações obtidas por meio das denúncias.

O Relatório Diário é um relatório fixo e reúne algumas denúncias sinalizadas como "Importantes" e outras difundidas para a SSI. Esse relatório contém denúncias do dia anterior e é encaminhado todos os dias pela manhã para o Secretário de Segurança, para o Subsecretário de Inteligência e para o Governador. Ele deve conter apenas duas páginas, independentemente da quantidade de denúncias sinalizadas.

O Relatório Diário contém denúncias sobre fatos que estão para acontecer "como um alerta para as autoridades”, conforme declarou o gerente de Análise, ou denúncias de ameaças a autoridades e policiais, como invasões de facções em comunidades dominadas por facções rivais, por exemplo. Também são incluídas denúncias sobre fatos ocorridos, como algo ligado ao tráfico, e outros assuntos considerados relevantes segundo os que irão recebê-los. Portanto, são selecionadas através de uma triagem apenas as denúncias que os analistas acreditam ser significativas para os que irão recebê-las, tarefa essa realizada pelo gerente de Análise.

Os Relatórios Mensais também são encaminhados para seus parceiros. Estes são tratados como uma espécie de "ajuda" que a Central Disque-Denúncia oferece a seus parceiros como uma forma de retribuir seus investimentos financeiros. Já os relatórios eventuais são aqueles produzidos quando solicitados, ou produzidos pelo próprio Setor de Análise para as autoridades, sobre assuntos muito denunciados em determinado período, podendo conter tabelas, gráficos e análises georeferenciadas com mapas. Dentre esses relatórios está o Informe, uma espécie de relatório simplificado. Ele contém no máximo quatro páginas e uma análise reduzida das denúncias solicitadas ou que foram analisadas autonomamente e entregues aos órgãos competentes.

Os outros tipos de relatórios eventuais são produzi- dos de acordo com o que é solicitado ou com a subjetividade do Gerente de Análise ao identificar um fluxo maior de denúncias sobre determinado fato não em evidência na mídia ou que está sendo solicitado pelas autoridades e instituições policiais. Nessa atividade, o conteúdo a ser abordado nos relatórios segue o padrão "A.P.O.L.O", isto é "Assunto, Pessoa, Organização, Lugar e Objeto", padrão este sugerido pela SSI através da Doutrina de Inteligência de Segurança Pública do estado do Rio de Janeiro (DISPERJ).

A estrutura desses relatórios não é universalmente padronizada e sua estrutura varia de acordo com o que é solicitado. Cada um possui sua especificidade e uma padronização mínima de acordo com os temas e conteúdos. Porém, apesar de não haver uma padronização universal, como algumas informações se assemelham ao tratarem de determinados temas, o relatório acaba dispondo de uma certa padronização. Para o gerente de análise "deveria ter uma padronização dos relatórios, porém não o fazemos. Mas, por fazermos isso há muito tempo, acabamos fazendo de forma parecida".

São importantes para a produção de relatórios denúncias que apresentam informações detalhadas. Muitas vezes elas se repetem, porém algumas possuem informações que ajudaram na produção dos relatórios. Quanto mais detalhada uma denúncia, melhor será para a produção de relatórios. Estes detalhamentos se referem à quantidade de informações obtidas.

\section{Compartilhamento e Particularização da Informação}

As atividades do Setor de Análise são amplas, não se restringindo à realização de pesquisas e à produção de relatórios. Além de coordenar a produção de relatórios, o Gerente de Análise atua como uma espécie de "relações públicas". É ele quem vai a reuniões e a palestras em que apresenta a instituição e as atividades por ela desenvolvidas. Por ser aquele que está mais próximo dos Agentes da Segurança Pública em função desses eventos externos e disposto a lidar com os membros de todas as divisões das instituições policiais, o Gerente do Setor de Análise é procurado por policiais, comandantes de batalhões e delegados através de outros meios de comunicação, como o aplicativo de celulares Whatsapp, para pro- 
duzir pesquisas e relatórios, além de manter relações com policiais e membros dessas instituições para que possam manter atuações contínuas e recíprocas.

A Central Disque-Denúncia possui um setor de Difusão, responsável por encaminhar as denúncias aos órgãos nas quais elas se enquadram. Esse setor é composto por policiais militares ou bombeiros militares, administrativamente ligados à SSI. No que diz respeito às denúncias imediatas, o setor de Difusão trabalha com o princípio da oportunidade, ou seja, quando mais rápido as denúncias são encaminhadas, mais rápida será a atuação dos órgãos acionados.

Como a instituição se orienta pela coleta indiferenciada de informações e o seu compartilhamento, essa difusão é múltipla, ou seja, o encaminhamento das denúncias é feito para a maior quantidade possível de órgãos e instituições. 0 compartilhamento das informações, por sua vez, costuma gerar cobranças por parte dos policiais no que diz respeito a detalhamentos. Apesar das denúncias serem encaminhadas por um setor que possui a atribuição da Difusão, o Setor de Análise recebe demandas dos agentes da segurança pública por uma difusão particularizada de denúncias.

Essa busca das autoridades policiais por informações detalhadas é decorrente de uma forma tradicional de organização e controle da informação, "na qual a desordem e a particularização do conhecimento são mecanismos fundamentais para a distribuição e manutenção do poder (...)" (Mendes de Miranda, 2004, p. 6).

Michel Foucault (2012) abordou a relação existente entre poder e saber afirmando que o saber produz poder e que essa relação não natural, mas derivada de relações e práticas sociais. Neste caso, a particularização de informações buscada por instituições policiais se constitui em uma forma de obter e estabelecer poder através de um saber centrado na própria produção de informações.

Temos antes que admitir que o poder produz saber (...); que poder e saber estão diretamente implicados; não há relação de poder sem constituição correlata de um campo de saber, nem saber que não suponha e não constitua ao mesmo tempo relações de poder. (Foucault, 2012, p. 30).
Desta forma, pude perceber que os agentes da segurança pública, principalmente policiais, tentam incorporar às atividades da Central Disque-Denúncia características de seu trabalho cotidiano, como uma tentativa de tomar para si informações que seriam compartilhadas. Ou seja, apesar da implementação do Programa Delegacia Legal, no final da década de 1990, visando à modernização e transparência do trabalho policial e das informações a partir de um trabalho informatizado (Mendes de Miranda et al, 2007; Gomes, 2008), as práticas policiais ainda se direcionam para a particularização da informação, como acontecia nas delegacias tradicionais.

\section{Conclusão}

Ao longo de sua existência, a Central Disque-Denúncia se adaptou conforme as demandas sociais fluminenses (Moraes, 2001) e se estabeleceu como uma importante "arma do cidadão" (Moraes, 2006). Apesar do viés negativo das denúncias em nossa cultura institucional (Misse, 2008), o "DD" se afirma como uma intervenção na segurança pública a partir dos interesses da sociedade e não das disputas corporativas das diferentes instituições de segurança e justiça criminal. O contraste com a perspectiva da cultura inquisitorial, resquícios de uma herança colonial (Kant de Lima, 2001), permite ampliar a reflexão sobre formas distintas de produzir e gerir a informação, preservando o anonimato e uma relação de reciprocidade contínua com os denunciantes.

A coleta e a organização das informações realizadas pela Central Disque-Denúncia são baseadas na relação de confiança com os denunciantes, não havendo suspeição entre a instituição e a sociedade, e o compartilhamento da informação é fundamental para o funcionamento da instituição, seja interna ou externamente. Suas práticas institucionais são muito distintas das dinâmicas das instituições de segurança pública e da justiça criminal, tipicamente cartoriais (Mendes de Miranda, 2000) e particularizadas (Kant de Lima, 1995).

A finalidade da Central Disque-Denúncia é receber informações e produzir relatos. Como explicam seus membros, "sem a Central de Atendimento, o 'DD' não existe". Porém, as atividades do " $D D$ " não se restrin- 
gem somente a isto, sendo também desenvolvedoras de análises criminais pelos relatórios a partir das informações obtidas, negociando prestígio como forma de estabelecer acordos e alianças.

Desta forma, a Central Disque-Denúncia se estabeleceu como uma ferramenta de denúncia acessível aos denunciantes. A garantia do anonimato proporciona à sociedade um meio de compartilhar informações potencialmente relevantes para as polícias e resguarda a integridade daqueles que têm medo de denunciar. Além disso, se tornou uma das principais instituições cariocas detentoras de informações para apoiar o desenvolvimento de ações policiais não violentas.

A relação dos agentes do Estado com as políticas envolvidas nessa experiência tem demonstrado formas alternativas à inquisitorialidade de nossas instituições. Compreender essas formas de produção e de gestão da informação nos permite qualificar essa iniciativa e refletir sobre os desafios da segurança pública no Brasil a partir do ponto de vista da sociedade.

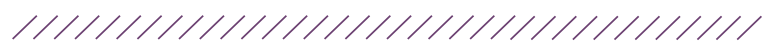

\section{Referências}

Caruso, H. (2003). A denúncia anônima como ferramenta de ação policial - Disque Denúncia: uma experiência em curso. In: Políticas Públicas de Justiça Criminal e Segurança Pública. EDUFF. ISP. RJ.

Disque Denúncia. O QUE SOMOS. Disponível em: http://www.disquedenuncia.org.br/o_que_somos.php. Acesso em: 26/01/2015.

Dupret, B. (2011). A intenção em ação: Uma abordagem pragmática da qualificação penal num contexto egípcio. Revista ética e filosofia política, vol. 12, p. 109-140.

Ferreira, L. C. M. (2015). Pessoas Desaparecidas: uma etnografia para muitas ausências. Rio de Janeiro: Editora UFRJ.

Foucault, M. (2012). Vigiar e Punir: Nascimento da prisão. 40. ed. Petrópolis: Vozes.

Freixo, A. S. (2013). Verificar para Informar? A construção da verdade extrajudicial numa Delegacia de Polícia. Dissertação. Programa de Pós-Graduação em Direito Constitucional. Niterói: Universidade Federal Fluminense.

Garfinkel, H. (2014). "Boas" razões organizacionais para "maus" registros clínicos. In: Programa de Pós-Graduação em Ciências Sociais - UFJF vol. 9, $\mathrm{n}^{\circ} .2$ jul./dez.

Gomes, A. S. (2008). Transparência, democratização e otimização das informações com a implementação do sistema informatizado da Delegacia Legal. In: Políticas Públicas de Segurança, Informação e Análise Criminal. Niterói: EdUFF, p. 27-50.

Holloway, T. H. (1997). Polícia no Rio de Janeiro - Repressão e resistência numa cidade do século XIX. Rio de Janeiro, Fundação Getúlio Vargas.

Kant de Lima, R. (1995). A polícia na cidade do Rio de Janeiro. Rio de Janeiro: Forense.

(1999). Polícia, Justiça e Sociedade no Brasil: Uma Abordagem Comparativa dos Modelos de Administração de Conflitos No Espaço Público. In: Revista de Sociologia e Política. $N^{\circ}$ 13: 23-38 Nov. Curitiba.

(2001). Administração de conflitos, espaço público e cidadania: uma perspectiva comparada. Civitas - Revista de Ciências Sociais, Ano 1, nº. 2, p. 11-16, dezembro.

Mendes de Miranda, A. P. (2000). Cartórios: onde a tradição tem registro público. Antropolítica (UFF), Niterói, vol. 8, p. 59-75. 
. (2004). Gestão da informação, análise criminal e sentimento de (in) segurança: considerações para a construção de políticas públicas de segurança. Simpósio da Rede Interdisciplinar de Estudos Comparativos (RIEC): Direito, Justiça e Segurança Pública - Isaac Joseph, o espaço público e as políticas públicas. VIII Congresso Luso-Afro Brasileiro de Ciências Sociais. Coimbra.

Mendes de Miranda, A. P.; Beraldo De Oliveira, M.; Ferreira Paes,V. (2007). Antropologia e Políticas Públicas: Notas sobre a avaliação do trabalho policial. Cuadernos de antropología social, $\mathrm{n}^{\circ}$. 25, p. 51-70, jul.

Misse, M. (2008). Sobre a Construção Social do Crime no Brasil: esboços de uma interpretação. In.: Acusados e Acusadores. Rio de Janeiro: Revan, p. 13-32.

Moraes, L. P. B. de. (2001). Imagens do caos - Percepções de ordem e segurança pública a partir das experiências da Central Disque-Denúncia do Rio de Janeiro. Monografia - Niterói: UFF.

. (2006). Disque-Denúncia: a arma do cidadão - Um estudo sobre os processos de construção da verdade a partir das experiências da Central Disque-Denúncia do Rio de Janeiro. Dissertação de mestrado - Niterói: UFF.

Paes, V. F. (2010). Como se contam crimes: um estudo sobre a construção social do crime no Brasil e na França. Tese de Doutorado - Rio de Janeiro: UFRJ.

Souza, E. G. A. (2008). Formas de Administração de Conflitos no Espaço Público: Casos de Feijoada da polícia da cidade do Rio de Janeiro. In: $26^{a}$ Reunião Brasileira de Antropologia. Porto Seguro.

Souza, J. DE et al. (2015). CONTROLANDO O INCONTROLÁVEL: A aplicação das regras de atendimento na construção da compreensão mútua entre clientes e atendentes em um call center. Linguagem em (Dis)curso, vol. 15, n'. 1, p. 13-32.

Telles, V. Da S.; Hirata, D. (2007) Cidade e práticas urbanas: nas fronteiras incertas entre o ilegal, o informal e o ilícito. Estudos Avançados (USP. Impresso), vol. 21, p. 173-192.

Vianna, M. Dos S.; Geraldo, P. H. B. (2017). A Boa Denúncia: A construção dos relatos para a produção da informação na Central Disque-Denúncia. Confluências Revista Interdisciplinar de Sociologia e Direito, vol. 19, nº. 1, p. 48-63, 21 abr. 